\title{
BMJ Open Article placement order in rheumatology journals: a content analysis
}

\author{
Sarah Stewart (D) , Greg Gamble, Andrew Grey (D) , Nicola Dalbeth
}

To cite: Stewart S, Gamble G, Grey $A$, et al. Article placement order in rheumatology journals: a content analysis. BMJ Open 2020;10:e034550. doi:10.1136/ bmjopen-2019-034550

- Prepublication history and additional material for this paper are available online. To view these files, please visit the journal online (http://dx.doi. org/10.1136/bmjopen-2019034550).

Received 25 September 2019 Revised 25 February 2020 Accepted 06 May 2020

\section{Check for updates}

(C) Author(s) (or their employer(s)) 2020. Re-use permitted under CC BY-NC. No commercial re-use. See rights and permissions. Published by BMJ.

Department of Medicine University of Auckland, Auckland, New Zealand

Correspondence to Dr Nicola Dalbeth n.dalbeth@auckland.ac.nz

\section{ABSTRACT}

Objectives To analyse variables associated with article placement order in serial rheumatology journals.

Design Content analysis.

Setting Original articles published in seven rheumatology journals from 2013 to 2018.

Primary and secondary outcome measures The following data were extracted from 6787 articles: order number of article in issue, gender of first and last author, geographical region, industry funding, research design and disease category. Cumulative density function plots were used to determine whether article placement distribution was different from the expected distribution. ORs for articles published in the first three places of an issue compared with the last three places were calculated. Altmetric Score and downloads were meta-analysed. Results Article placement order did not associate with author gender or geographical region but was associated with funding source and research design. In addition, articles about rheumatoid arthritis were more likely to be ordered at the front of issues $(p<0.001)$. Articles about crystal arthritis, systemic lupus erythematosus, vasculitis, pain syndromes and paediatric rheumatic diseases were more likely to be ordered at the end of issues (all $p<0.001)$. Association of article placement order with disease category was observed only in journals with tables of contents grouped by disease. Articles ordered in the first three places had higher Altmetric and download rates, than articles in the last three places.

Conclusions Author gender and geographical region do not influence article placement order in serial rheumatology journals. However, bias for certain disease categories is reflected in article placement order. Editorial decisions about article placement order can influence the prominence of diseases.

\section{INTRODUCTION}

The strong preference for items ordered first, and the important effect of list order on choice, is well recognised in consumer-based research. $^{1-3}$ In online searches for health information, $97 \%$ of selected links were displayed in the first 10 results, while only $2 \%$ were from the second or following pages. ${ }^{4}$ For online academic repositories, earlier listed articles were downloaded more frequently than later listed articles. ${ }^{5}$ These primacy effects, which increase when lists are longer,

\section{Strengths and limitations of the study}

This is the first study to assess the relationship of article placement order in serial medical journals with author gender, geographical region of affiliated institution, industry funding, research design or disease category.

- This content analysis included 6787 articles from general rheumatology journals.

- This study also analysed the impact of article placement order on research prominence, including Altmetric Scores and download rate.

- This analysis did not explore other factors that may have contributed to article placement order such as the originality of the study findings or the presence of 'star' authors.

may occur because earlier items, or those at the top of tables of contents, are more visible and more likely to be seen and read. ${ }^{5}$

In academic publishing, the ordering of articles within a journal issue also affects the prominence achieved by that research. Earlier listed articles received more citations over a 25-year period in a single journal. ${ }^{7}$ The impact of ordering was also evident in an analysis of emails sent to subscribers disseminating recent research papers listed in random order; with the first paper having a $33 \%$ increase in views, $29 \%$ increase in downloads and $27 \%$ increase in citations, regardless of research quality. ${ }^{8}$

A number of systemic biases have been reported in academic publishing. These include preferential lead and senior authorship of men, ${ }^{9} 10$ higher acceptance rates for articles from the USA and Europe,$^{9}{ }^{11}$ preferential publication of industry-funded research ${ }^{12}$ and disease privileging, wherein particular diseases receive preferential research funding and publication. ${ }^{13-15}$ It is unknown whether these systemic biases are reflected in article placement order within medical journals. We analysed serial rheumatology journals for relationships between article placement order and gender of the 
lead and senior authors, geographical region of the affiliated institution, industry sponsorship and disease category.

\section{METHODS}

\section{Patient and public involvement}

There was no patient or public involvement in the design, or conduct, or reporting, of this research.

\section{Identification of journals and articles for inclusion}

This was a cross-sectional content analysis of original articles published in general rheumatology journals. Journals were included if they produced regular issues, reported original research and had 2016 Thomas Reuters Impact Factors of $>3$.0. Journals were excluded if they published review articles only, were disease-specific (eg, Lupus, Osteoarthritis and Cartilage) or produced no issues. The following seven general rheumatology journals met the above criteria and were included: Annals of the Rheumatic Diseases, Arthritis $\mathcal{E}$ Rheumatology, Arthritis Care $\mathcal{E}$ Research, Seminars in Arthritis and Rheumatism, Rheumatology, Journal of Rheumatology and Joint Bone Spine. Characteristics of the included journals are shown in online supplementary table 1 .

All original articles published in the included journals in a 5-year period from June 2013 to June 2018 were included in the analysis. To be included, articles could be full or concise reports, and report on original basic science or clinical research, including systematic reviews and meta-analyses. Articles were excluded if they were from a disease-specific thematic issue or supplement, were narrative reviews, recommendations, guidelines, letters or meeting reports.

\section{Data extraction}

Data extraction was undertaken between June and December 2018. The following information was extracted for each included article: order number of article in the issue; gender of lead (first) author; gender of senior (final) author; geographical region of affiliated institution (for the first author); industry-funding category (industry-funded and industry-initiated, industry-funded and investigator-initiated, not industry-funded); research design (basic science, other clinical, randomised controlled trial, systematic literature/meta-analysis); and, if available, the Altmetric Score and number of downloads. The number of citations was not assessed because of the short time period between publication and data extraction. If author gender could not be determined by first name or by an internet search of the author's affiliated institution profile page, then the author's first name was entered into https:/ /api.genderize.io/?name=, which returns the gender and probability of certainty. Probabilities $<0.5$ were labelled as 'unknown' and not included in the gender-related analysis. If articles were authored by a single author, then this author's gender was entered under first author. Funding was assessed by review of funding statements, disclosures and author affiliations. Industry-funded studies were categorised as industryfunded and industry-initiated or industry-funded and investigator-initiated, based on these statements. Studies with no evidence of industry funding were categorised as not industry-funded.

Articles were coded according to the following 13 disease categories: ankylosing spondylitis and other spondyloarthropathy, crystal arthritis, osteoarthritis, miscellaneous rheumatic disease, paediatric rheumatology, pain syndromes, psoriatic arthritis, rheumatoid arthritis, systemic lupus erythematosus, systemic sclerosis/scleroderma, other connective tissue disorders, vasculitis and not disease-specific. The title of each article was used to determine the disease category. If there was uncertainty about the disease category from the title, then the abstract and/or full paper were reviewed.

To ensure standardisation in data extraction, two authors (SS, ND) independently reviewed eligible papers from 10 randomly selected issues. A total of 208 articles were reviewed, with kappas of 1.00 for author gender, geographical region and industry-funding category, while disease category had a kappa of $0.84(86.1 \%$ agreement $(95 \%$ CI $81.0 \%, 90.5 \%))$. All disease category disagreements were discussed to reach a consensus and a set of rules for categorising was established. The exercise was then repeated in which the two authors reviewed disease categories in a further five randomly selected issues totalling 85 articles, with a kappa of 0.99 (98.8\% agreement $(95 \%$ CI $94.3 \%, 99.9 \%))$ for disease category. A single reviewer (SS) then independently extracted the data.

\section{Data analysis}

The primary analyses assessed the relationships between article placement order and: gender of first authors, gender of last authors, geographical region (Europe, North America, Other), industry-funding categories (industry-funded and industry-initiated, industryfunded and investigator-initiated, not industry-funded), research design (basic science, other clinical research, randomised controlled trial, systematic literature review/ meta-analysis) and disease categories. In order to identify whether these factors were associated with article placement order within journal issues, each article within each issue was assigned a Standard Article Placement Index (SAPI), which was defined as the order of the article in the issue/total number of articles in the issue. For example, the first article in an issue of 21 articles was given an SAPI of $1 / 21=0.0476$ and the last article $21 / 21=1$. This metric allowed standardisation of article placement order within issues with the expectation that the number of articles within each issue would vary widely across different journals. For example, the SAPI could scale between article placement in a journal issue of 5 articles and one with 50 articles. Therefore, this metric addressed the large variation in the number of articles between different journal issues and overcame the potential issue of skewed average article placement order data 
resulting from issues with large numbers of articles. The SAPI as a placement metric enabled the examination of article placement order without an assumption that the mean (or median) article placement order was different. Cumulative distribution functions (CDFs) of SAPIs were analysed to determine the associations between article placement order and author gender, geographical region, industry funding and disease category. A uniform distribution would be expected if there was no association with article placement order: deviations from the expected uniform distribution would support an association with article placement order. Due to the potential over-sensitivity of this test, ${ }^{16}$ the effect sizes (D) were also computed with values ranging from 0 (no difference in distribution of SAPI between comparisons) to 1 (large difference in distribution of SAPI between comparisons) to provide further description of the deviations between the observed distributions. To determine whether the distribution of SAPIs for each variable was different from a uniform distribution CDF (expected distribution if no bias reflected in article placement order), the area under the curve (AUC) of the observed CDF and uniform distribution CDF were each calculated using a trapezoidal method and the difference between these estimated for each of the variable categories. Mean differences between the observed $\mathrm{CDF}$ and the uniform distribution CDF AUCs were computed from bootstrapped samples (500 replicates, sampled with replacement) and 95\% CIs estimated as the 2.5th and 97.5th percentile of the bootstrap distribution. $\mathrm{P}$ values were calculated for each category from these CIs using the method of Altman and Bland. ${ }^{17}$ This analysis method allowed for an assumptionfree comparison of the observed and expected distributions of SAPIs. ${ }^{18}$ CDF-based comparisons are estimates and do not systematically increase or decrease with sample size. The estimated CDF, like an estimated mean, is unbiased at any sample size. The estimation of the CDF (like estimation of a mean) assumed only that each variable examined provided some incremental information; that is, that collinearity was not close to perfect. ${ }^{19}$ Unlike the comparison of a central tendency statistic (ie, mean or median order placement), comparing these distributions allowed testing of any early and late article placement (bimodal) clustering (primacy and recency) as well as a uniform distribution of placement. CDF plots of SAPIs also provided a visually clear representation of article placement order and potential differences between groups.

A secondary analysis was undertaken to further explore article placement order, in which mid-p exact $p$ values were computed to compare the proportion of articles appearing in at least one of the first three places of an issue compared with at least one of the last three places of an issue for genders of first and last authors, geographical region, industry-funding category and each disease category. ORs and their 95\% CIs were also computed for articles in the first three places versus last three places of an issue.
As some journals presented their content grouped by disease category, additional analyses were undertaken to determine whether article placement order of disease categories was different between journals which presented content grouped by disease category versus journals without disease category content grouping. This was tested statistically using CDF plots of SAPI distributions, two-sample Kolmogorov-Smirnov Z tests and effect sizes (KS D) as described above.

To further explore factors associated with article placement order, a supplementary post hoc analysis was undertaken to compare the median SAPIs between genders, geographical regions, industry-funding categories and disease categories using Mann-Whitney U or KruskalWallis tests, as appropriate. Mann-Whitney U tests were also undertaken to determine whether article placement order for articles about rheumatoid arthritis differed from other disease categories. Cohen's d were computed for each comparison as measures of effect size with scores of 0.2 considered small, 0.5 considered median and 0.8 considered large. ${ }^{20}$

Finally, to determine the impact of article placement order on Altmetric Scores and article download rates (as available), meta-analyses were used to determine differences in the means for each variable between the first and last three articles in journal issues. Altmetric Scores were provided by Arthritis E Rheumatology, Annals of the Rheumatic Diseases, Rheumatology and Arthritis Care $\mathcal{E}$ Research. Annals of the Rheumatic Diseases, Rheumatology and The Journal of Rheumatology had article download data available, but for the latter two journals, the data were available in only the 6 months prior to data extraction. Therefore, analyses of article downloads were undertaken for Annals of the Rheumatic Diseases only. For Altmetric Scores, which generally do not change over time, mean scores were calculated by total Altmetric Scores/total number of articles. For downloads, which are time dependent, rates were calculated by total number of downloads/total article-years from time of publication to time of data extraction. These analyses were undertaken within disease categories, adjusted by journal, as appropriate, and weighted using the inversevariance method. Random effects models were used.

All analyses were performed in SPSS V.25 (IBM Corp) and SAS V.9.4 (SAS Institute). All tests were two-tailed and false discovery rate-adjusted $\mathrm{p}$ values ${ }^{21}$ were computed for all analyses with an alpha level of $<0.05$ considered significant.

\section{RESULTS}

\section{Characteristics of included articles}

First authors were men in $3250(47.9 \%)$ articles, women in $3517(51.8 \%)$ articles and unknown in $20(0.3 \%)$ articles. Last authors were men in $4412(65.0 \%)$ articles, women in $2359(34.8 \%)$ articles and unknown/not applicable in $16(0.2 \%)$ articles. The geographical region was Europe in 3486 (51.4\%) articles, North America in 2177 (32.1\%) articles and other in $1124(16.6 \%)$ articles. Five hundred 


\section{A. First author gender}

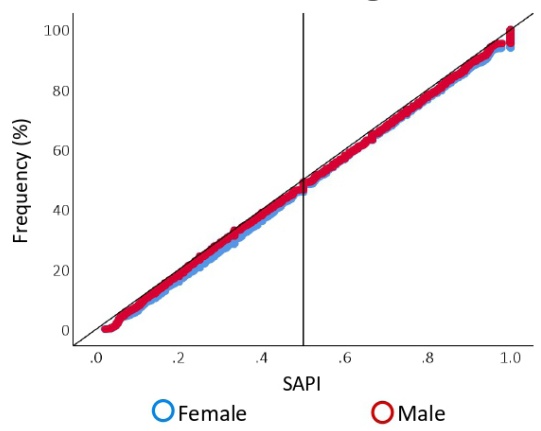

B. Senior author gender

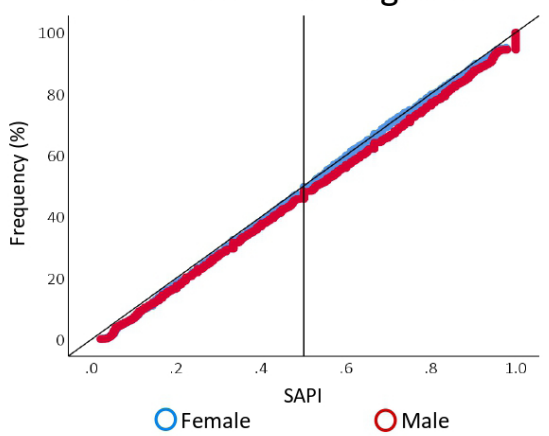

C. Geographical region

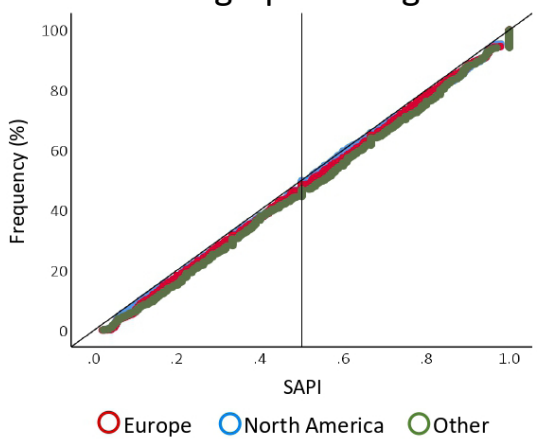

and ninety-six $(8.8 \%)$ articles were industry-funded and industry-initiated, $640(9.4 \%)$ were industry-funded and investigator-initiated and $5551(81.8 \%)$ were not industryfunded. Of the included papers, 1395 (20.6\%) reported basic research, $4466(65.8 \%)$ were categorised as other clinical research studies, $488(7.2 \%)$ were randomised controlled trials and 438 (6.5\%) were systematic literature reviews or meta-analyses. Disease categories were rheumatoid arthritis $(\mathrm{n}=1946,28.7 \%)$, osteoarthritis $(\mathrm{n}=773,11.4 \%)$, systemic lupus erythematosus $(\mathrm{n}=642$, $9.5 \%)$, ankylosing spondylitis $(\mathrm{n}=496,7.3 \%)$, paediatric rheumatology $(\mathrm{n}=443,6.5 \%)$, systemic sclerosis $(\mathrm{n}=433$, $6.4 \%)$, not disease-specific $(\mathrm{n}=422,6.2 \%)$, vasculitis $(\mathrm{n}=362,5.3 \%)$, other connective tissue disease $(\mathrm{n}=339$, $5.0 \%)$, miscellaneous $(\mathrm{n}=277,4.1 \%)$, crystal arthritis $(\mathrm{n}=269,4.0 \%)$, psoriatic arthritis $(\mathrm{n}=242,3.6 \%)$ and pain syndromes $(n=143,2.1 \%)$. The specific diseases which were categorised under crystal arthritis, other connective tissue disease and miscellaneous are shown in online supplementary table 2 .

\section{Distribution of article placement within issues}

Inspection of the CDF plots showed no association of article placement order with author gender or geographical region. However, differences in article placement order were observed for funding source, research design and disease category (figure 1, online supplementary table 3). Industry-funded and industry-initiated studies and industry-funded and investigator-initiated studies were more likely to be placed towards the front of journal issues. Similarly, randomised controlled trials were placed towards the front of issues, while basic science research articles were placed towards the back of issues. Figure 2 and table 1 display the differences in article placement order for disease category. Articles about rheumatoid arthritis were more likely to be placed towards the front of issues. The placement of articles about ankylosing spondylitis, osteoarthritis and psoriatic arthritis conformed to a uniform distribution. Articles about systemic lupus erythematosus, other connective tissue diseases, crystal arthritis, systemic sclerosis, vasculitis, paediatric rheumatology and pain syndromes were more likely to be placed towards the back of issues.

\section{Articles in the first and last three places of an issue}

There were no significant differences in the proportion of articles in the first versus last three places of an issue for author gender, geographical regions or industry-funding category (online supplementary table 4). However, consistent with the CDF analysis, differences for disease category were observed (figure 3, online supplementary table 4 ). There was a significantly greater proportion of articles in the first three compared with the last three places of an issue for rheumatoid arthritis $(35.6 \%$ vs $8.7 \%, \mathrm{p}<0.001)$ with an OR $(95 \% \mathrm{CI})$ of $5.77(4.80$, $6.92)$. There was a similar proportion of articles in the 


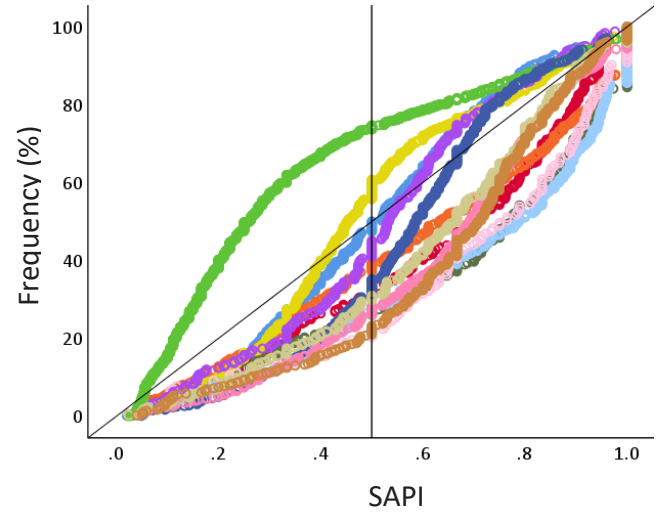

Ankylosing spondylitis Ocrystal arthritis OMiscellaneous Not disease-specific Osteoarthritis Paediatric rheumatology Pain syndromes $O$ Psoriatic arthritis $\mathrm{Rheumatoid}$ arthritis Systemic lupus erythematosus Systemic sclerosis Other connective tissue disease Vasculitis

Figure 2 Cumulative distribution function plots of standardised article placement indices (SAPI) for each disease category. Left-deviated distributions suggest prioritisation towards the front of journal issues.

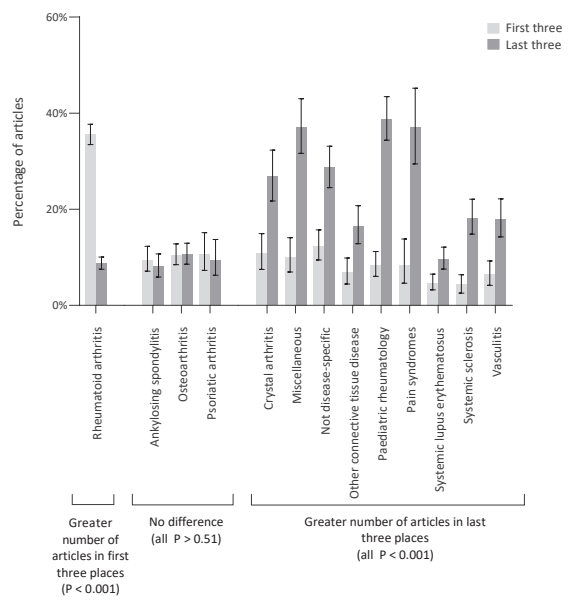

Figure 3 Percentage of articles (per disease category) published in first three and last three places of an issue ( $p$ values indicate difference between proportions of articles in first and last three places of an issue).

first three and last three places of an issue for ankylosing spondylitis, osteoarthritis or psoriatic arthritis. There was a significantly lower proportion of articles in the first three compared with the last three places of an issue for crystal arthritis ( $10.8 \%$ vs $26.8 \%)$, other connective tissue diseases $(6.8 \%$ vs $16.5 \%)$, paediatric rheumatology $(8.4 \%$ vs $38.8 \%)$, pain syndromes $(8.4 \%$ vs $37.1 \%)$, systemic lupus erythematosus $(4.7 \%$ vs $9.7 \%)$, systemic sclerosis $(4.4 \%$ vs $18.2 \%)$ and vasculitis $(6.4 \%$ vs $18.0 \%)$ (all

Table 1 Difference in distribution of standard article placement indices (SAPIs) from a uniform distribution for each disease category

\begin{tabular}{|c|c|c|c|c|c|}
\hline & \multirow[b]{2}{*}{$\mathbf{N}(\%)$} & \multirow{2}{*}{$\begin{array}{l}\text { SAPI, mean } \\
\text { (SD) }\end{array}$} & \multicolumn{2}{|c|}{ Difference in AUC between CDF and uniform distribution } & \multirow{2}{*}{$\begin{array}{l}\text { Effect size } \\
\text { (KS D)† }\end{array}$} \\
\hline & & & Mean $(95 \% \mathrm{Cl})^{*}$ & FDR-adjusted $p$ & \\
\hline Ankylosing spondylitis & $496(7.3)$ & $0.51(0.24)$ & $+0.00(-0.02,+0.01)$ & 0.94 & 0.10 \\
\hline Miscellaneous & $277(4.1)$ & $0.68(0.29)$ & $-0.18(-0.20,-0.15)$ & $<0.001$ & 0.30 \\
\hline Not disease-specific & $422(6.2)$ & $0.61(0.30)$ & $-0.09(-0.10,-0.07)$ & $<0.001$ & 0.15 \\
\hline $\begin{array}{l}\text { Paediatric } \\
\text { rheumatology }\end{array}$ & $443(6.5)$ & $0.69(0.28)$ & $-0.19(-0.23,-0.18)$ & $<0.001$ & 0.29 \\
\hline Pain syndromes & $143(2.1)$ & $0.69(0.27)$ & $-0.18(-0.26,-0.15)$ & $<0.001$ & 0.30 \\
\hline Systemic sclerosis & $433(6.4)$ & $0.64(0.24)$ & $-0.14(-0.15,-0.12)$ & $<0.001$ & 0.23 \\
\hline Vasculitis & $362(5.3)$ & $0.65(0.24)$ & $-0.15(-0.18,-0.12)$ & $<0.001$ & 0.27 \\
\hline
\end{tabular}

*Positive differences indicate deviations from a uniform distribution above the uniform distribution function (ie, article placement towards the front of an issue), while negative differences indicate deviations from a uniform distribution below the uniform distribution function (ie, article placement towards the back of an issue).

†From one-sample Kolmogorov-Smirnov Z test.

AUC, area under the curve; CDF, cumulative distribution function; FDR, false discovery rate; SAPI, standard articles placement index. 
$\mathrm{p} \leq 0.001)$. Differences in the proportion of articles in the first versus last three places of an issue were also observed for research type, with a significantly higher proportion of articles in the first three compared with the last three places of an issue for other clinical research $(17.0 \%$ vs $13.6 \%)$, randomised controlled trials $(26.4 \%$ vs $10.9 \%)$ and systematic literature reviews/meta analyses $(24.2 \%$ vs $16.7 \%$ ) (all $\mathrm{p} \leq 0.003$ ) and a significantly lower proportion of articles in the first three compared with last three for basic science research $(7.6 \%$ vs $26.2 \%, \mathrm{p}<0.001)$ (online supplementary table 4$)$.

\section{Journals with and without content grouped by disease category}

Arthritis $\mathcal{E}$ Rheumatology, Seminars in Arthritis and Rheumatism, Arthritis Care E Research and The Journal of Rheumatology grouped issue content by disease category with disease-specific tables of contents sections, while Annals of the Rheumatic Diseases, Rheumatology and Joint Bone Spine did not group issue content by disease category (online supplementary table 1). Journals with content grouped by disease showed an association between article placement order and disease category, whereas this was less evident for journals without content grouped by disease (figure 4). Comparisons between journals with and without content grouped by disease category demonstrated a significant difference in the SAPI distributions for every disease category, with articles on rheumatoid arthritis placed towards the front of issues, and articles on crystal arthritis, pain syndromes, paediatric rheumatology, systemic sclerosis and vasculitis placed towards the end of issues, in journals with content grouped by disease category (online supplementary table 5 ).

\section{Comparison of median SAPIs}

Post hoc analyses of the differences in median SAPIs between genders, geographical regions, industry-funding categories and disease categories are shown in online supplementary table 6 and online supplementary figure 1. Significant differences in article placement order were observed between disease categories, with all categories demonstrating greater median SAPIs (indicative of placement towards the back of journal issues) compared with rheumatoid arthritis (all $\mathrm{p}<0.001$ ).

\section{The impact of article placement order on Altmetric Scores and downloads}

The impact of article placement order was evident in the meta-analysis results, which showed a higher Altmetric Score (adjusted for journal) for articles published in the first three places of an issue compared with the last three (mean difference in Altmetric Score of 5.11, 95\% CI $1.50,8.71, \mathrm{Z}=2.78, \mathrm{p}=0.005$ ) (figure 5). The difference in Altmetric Scores varied across different disease categories $\left(\mathrm{I}^{2} 76 \% ; \mathrm{p}<0.001\right)$, with the largest difference between positioning in the first three places and positioning in the last three places being observed for articles about rheumatoid arthritis and psoriatic arthritis.
A. Journals with issue content grouped by disease

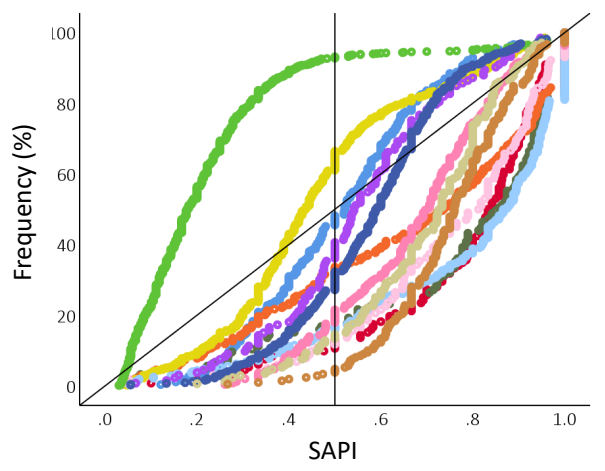

B. Journals without issue content grouped by disease

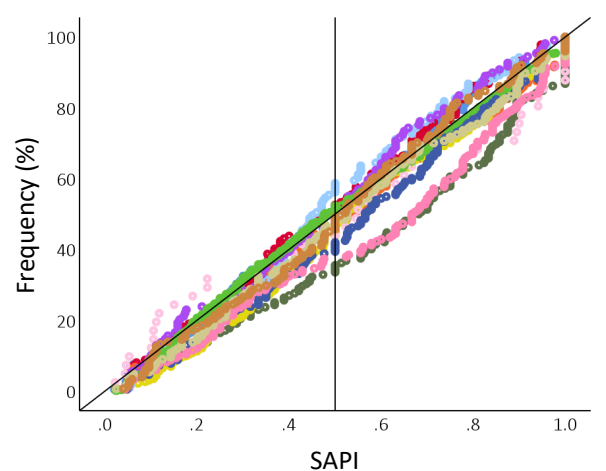

Ankylosing spondylitis Ocrystal arthritis $O^{\text {Miscellaneous }}$ Not disease-specific $\bigcirc$ Osteoarthritis $\bigcirc$ Paediatric rheumatology Pain syndromes $O$ Psoriatic arthritis ORheumatoid arthritis Systemic lupus erythematosus $\bigcirc$ Systemic sclerosis Other connective tissue disease $\bigcirc$ Vasculitis

Figure 4 Cumulative distribution function plots of standardised article placement indices (SAPIs) for each disease category for journals with (A) and without (B) contents grouped by disease. Left-deviated distributions suggest prioritisation towards the front of journal issues.

Similarly, meta-analysis showed that articles published in the first three places of an issue had a higher download rate compared with articles in the last three places of an issue (pooled rate difference $(95 \% \mathrm{CI}) 442.1$ (293.0, 591.2) downloads/article year, $\mathrm{Z}=5.81, \mathrm{p}<0.001$ ) (figure 5). The difference in download rate between the first and last three articles was similar across different disease categories $\left(\mathrm{I}^{2} 24 \% ; \mathrm{p}=0.21\right)$.

\section{DISCUSSION}

In this analysis of serial rheumatology journals, no relationship between article placement order and author gender or geographical region was observed. However, differences for funding source, research design and disease category were apparent. There was more frequent 
A. Differences in Altmetric scores between articles in first and last three places of an issue

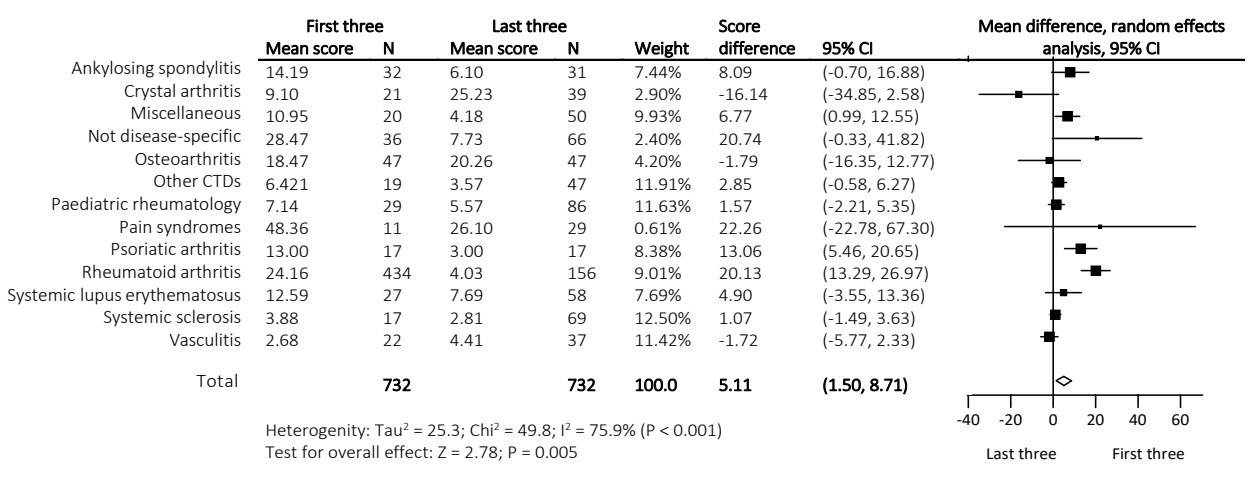

B. Differences in download rates between articles in first and last three places of an issue

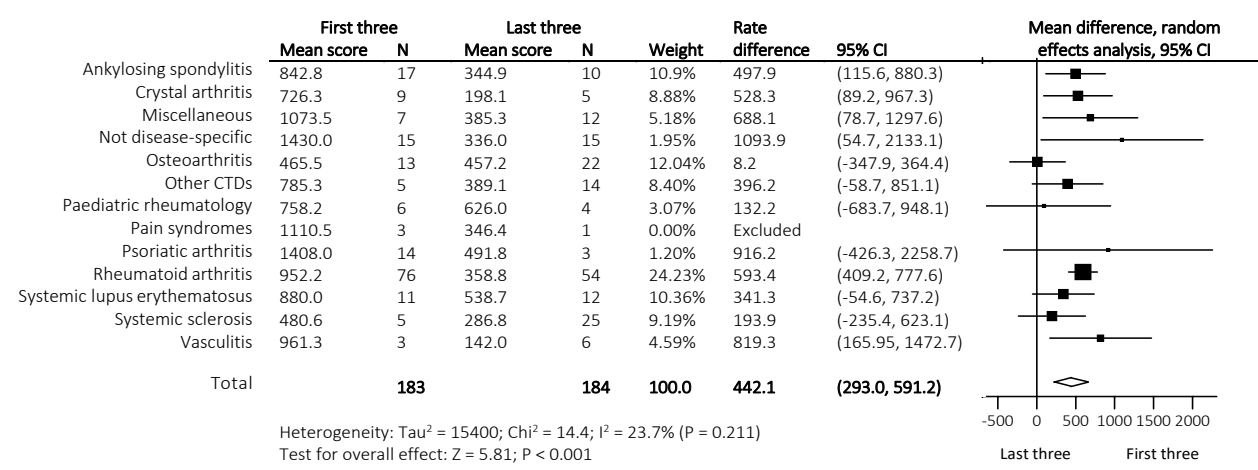

Figure 5 Forest plots showing the mean differences for each disease category for (A) Altmetric Scores and (B) download rates between articles published in the first versus last three places of an issue. Positive differences indicate a higher Altmetric Score/ download rate for articles published in one of the first three places of an issue. Differences in Altmetric Scores are adjusted for journal. Download data were available from one journal. CTD, connective tissue disease.

positioning of industry-funded studies and randomised controlled trials towards the front of journal issues. Articles about rheumatoid arthritis were also more frequently positioned towards the front of journal issues, while articles about crystal arthritis, other connective tissue diseases, paediatric rheumatology, pain syndromes, systemic lupus erythematosus, systemic sclerosis and vasculitis towards the back of issues. Analyses of Altmetric Scores and download rates suggested that article placement order influences research prominence, with earlier placed articles receiving more attention.

Medical journals are central to evidence-based practice and represent a key source of new knowledge for medical professionals. ${ }^{22}{ }^{23}$ Unbiased publication practices are important in allowing a variety of perspectives and emphases to expand the scope of research and clinical practice. Although bias has been previously reported in academic journals based on authorship ordering of genders, ${ }^{9} 10$ representation of geographical regions $^{911}$ and acceptance and time to publication based on industry sponsorship, ${ }^{12}$ our analysis showed that of these factors only industry-funding was associated with article placement order within serial rheumatology journals. This finding may reflect the placement of clinical trials towards the front of issues which likely made up the majority of industry-funded studies.

Articles about rheumatoid arthritis were preferentially placed towards the front of rheumatology journals, while other conditions, particularly pain syndromes, crystal arthritis, paediatric syndromes and connective tissue diseases were ordered towards the back. Rheumatoid arthritis was the disease category with the greatest number of articles, therefore giving it the greatest opportunity to be listed first, but our analyses accounted for the variation in article numbers between disease categories. Although rheumatoid arthritis is a very important rheumatic disease ${ }^{24}$ general rheumatology practice involves the diagnosis and treatment of a wide range of diseases. ${ }^{2526}$ General rheumatology journals should ideally reflect that diversity of clinical practice. A similar distribution of articles on each disease category would therefore be expected if there was no bias for disease category.

The reason for the observed differences in article placement for disease category is unclear. Disease privileging 
in other fields of medical research has been reported, with some prevalent diseases with high global impact being under-funded and under-researched. ${ }^{13-15}$ Crystal arthritis, osteoarthritis and pain syndromes are common; for example, prevalence estimates for US adults for gout are $3.9 \%,{ }^{27}$ for osteoarthritis are $13.4 \%^{28}$ and for low back pain are $26.4 \% .{ }^{29}$ However, these conditions may be viewed by rheumatologists and journal editors as less important or less severe. ${ }^{3031}$ Our analysis of article placement order, which did not reflect prioritising of diseases based on epidemiology or severity, emphasises the disconnect between the prevalence of disease and health research. These perceptions of some rheumatic diseases have the potential to impact attitudes in clinical practice and contribute to lower quality of care. ${ }^{31} 32$ Rheumatic diseases such as vasculitis, paediatric rheumatic disease and scleroderma are less common, but can lead to major morbidity and reduced quality of life. Improving the impact and accessibility of research published on 'lower priority' or less common rheumatic diseases may have an important impact on clinicians' understanding about and attitudes towards these conditions in clinical practice.

Differences in article placement order for disease category were particularly evident in journals with diseasespecific tables of contents sections within issues, rather than journals that did not group issue content by disease category. It has been suggested that grouping article content by disease category may improve the reader experience. ${ }^{33}$ However, such decisions have the potential to further reduce readers' exposure to diseases that are already under-studied or less well understood. Editorial decisions to remove grouping by disease category, or to cycle the order of disease category groups for each issue may be a simple solution to overcome bias for disease category reflected in article placement order.

In our analysis, articles appearing in the first three places of an issue had higher Altmetric Scores and download rates compared with articles appearing in the last three places of an issue. This finding may be attributed in part to the higher number of clinical trials published towards the front of issues, which generally have a greater impact, ${ }^{34}$ and is also consistent with prior studies which demonstrate the influence of the primacy effect on research prominence. ${ }^{6-8}$ Collectively, these findings indicate that articles placed at the front of journal issues receive greater prominence. The prominence and impact of research published in journals has an important role in not only providing information to improve knowledge and treatment, but also in financing further research ${ }^{35}$ and obtaining academic promotion. ${ }^{36}$

The current analysis has some limitations. First, Altmetric and download data were not available from all journals included in the analysis, and it is unclear whether similar differences are present across all journals. Second, citation rates were not evaluated because of the short time period between article publication and data extraction which would not have reflected true citation rates, which increase over time. Finally, this analysis did not explore other factors that may have contributed to article placement order such as quality, impact or originality of the study, or the presence of prolific or 'star' authors. ${ }^{37}$ Further research may also focus on identifying factors influencing editorial decisions about the placement order of articles about different diseases. For example, we did observe that basic science articles were placed towards the back of an issue, suggesting that editors prioritise clinical research over laboratory-based research. A strength of this paper is the use of multiple methods of analysis to explore the relationship between disease category and article placement order, including an analysis of the distribution of article placement, an analysis of the difference in proportion of articles appearing in the first and last three places of an issue and an analysis of the comparison of median article placement order between disease categories. Collectively, these results provide robust and detailed evidence that bias for industry-funded studies, clinical trials and for certain disease categories is reflected in article placement order.

In conclusion, author gender and geographical region do not influence article placement order in serial rheumatology journals. However, bias for certain disease categories is reflected in article placement order. Article placement order may have an impact on research prominence, including Altmetric Scores and download rate. Editorial choices about the serial position of articles within journals can influence prioritisation of certain diseases.

Contributors SS contributed towards acquisition, analysis and interpretation of the data. GG contributed towards design of the study and analysis and interpretation of the data. AG contributed towards design of the study and interpretation of the data. ND contributed towards design of the study, acquisition and interpretation of the data. All authors were involved in drafting of the work or revising it critically for important intellectual content. All authors approved the final version to be published and agree to be accountable for all aspects of the work.

Funding The authors have not declared a specific grant for this research from any funding agency in the public, commercial or not-for-profit sectors.

Competing interests ND has received consulting fees, speaker fees or grants from AstraZeneca, Horizon, Amgen, Arthrosi, Dyve Biosciences, Hengrui, Abbvie, Pfizer and Janssen, outside the submitted work. ND and SS work primarily in the field of gout research (a condition that was analysed in this research project). GG and $A G$ declare no competing interests.

Patient and public involvement Patients and/or the public were not involved in the design, or conduct, or reporting, or dissemination plans of this research.

Patient consent for publication Not required.

Provenance and peer review Not commissioned; externally peer reviewed.

Data availability statement Data are available upon reasonable request. All data collected for the purpose of this analysis will be made available immediately following publication upon reasonable request to the corresponding author.

Open access This is an open access article distributed in accordance with the Creative Commons Attribution Non Commercial (CC BY-NC 4.0) license, which permits others to distribute, remix, adapt, build upon this work noncommercially, and license their derivative works on different terms, provided the original work is properly cited, appropriate credit is given, any changes made indicated, and the use is non-commercial. See: http://creativecommons.org/ licenses/by-nc/4.0/.

ORCID iDs

Sarah Stewart http://orcid.org/0000-0002-9318-5627

Andrew Grey http://orcid.org/0000-0002-7803-0096 


\section{REFERENCES}

1 Chen E, Simonovits G, Krosnick JA, et al. The impact of candidate name order on election outcomes in North Dakota. Elect Stud 2014;35:115-22.

2 Becker SL. Why an order effect. Public Opin Q 1954;18:271-8.

3 Mantonakis A, Rodero P, Lesschaeve I, et al. Order in choice: effects of serial position on preferences. Psychol Sci 2009;20:1309-12.

4 Eysenbach G, Köhler C. How do consumers search for and appraise health information on the world wide web? qualitative study using focus groups, usability tests, and in-depth interviews. BMJ 2002;324:573-7.

5 A-u H, Ginsparg P. Positional effects on citation and readership in arXiv. J Assoc Inf Sci Technol 2009;60:2203-18.

6 Novarese M, Wilson CM. Being in the right place: a natural field experiment on list position and consumer choice. MPRA paper 48074. Germany: University Library of Munich, 2013.

7 Berger J, Jonah B. Does presentation order impact choice after delay? Top Cogn Sci 2016;8:670-84.

8 Feenberg D, Ganguli I, Gaulé P, et al. It's Good to Be First: Order Bias in Reading and Citing NBER Working Papers. Rev Econ Stat 2017;99:32-9.

9 Filardo G, da Graca B, Sass DM, et al. Trends and comparison of female first authorship in high impact medical journals: observational study (1994-2014). BMJ 2016;352:i847.

10 West JD, Jacquet J, King MM, et al. The role of gender in scholarly authorship. PLoS One 2013;8:e66212.

11 Edwards HA, Schroeder J, Dugdale HL. Gender differences in authorships are not associated with publication bias in an evolutionary Journal. PLoS One 2018;13:e0201725.

12 Lexchin J, Bero LA, Djulbegovic B, et al. Pharmaceutical industry sponsorship and research outcome and quality: systematic review. BMJ 2003;326:1167-70

13 Yegros A, Tijssen R, Abad-García M-F, et al. Drug research priorities at odds with global disease toll [Blog]. Nature Index, 2018. Available: https://www.natureindex.com/news-blog/drug-research-priorities-atodds-with-global-disease-toll [Accessed 6 Aug 2019].

14 Lobner K, Lanzkron S, Haywood C MHS. NIH and national Foundation expenditures for sickle cell disease and cystic fibrosis are associated with PubMed publications and FDA approvals. Blood 2013;122:1739.

15 Catalá-López F, García-Altés A, Alvarez-Martín E, et al. Does the development of new medicinal products in the European Union address global and regional health concerns? Popul Health Metr 2010;8:34-43.

16 Micceri T. The unicorn, the normal curve, and other improbable creatures. Psychol Bull 1989;105:156-66.

17 Altman DG, Bland JM. How to obtain the $P$ value from a confidence interval. BMJ 2011;343:d2304.

18 Bolland MJ, Gamble GD, Avenell A, et al. Baseline P value distributions in randomized trials were uniform for continuous but not categorical variables. J Clin Epidemiol 2019;112:67-76.
19 Storey JD, Tibshirani R. Statistical significance for genomewide studies. Proc Natl Acad Sci U S A 2003;100:9440-5.

20 Cohen J. Statistical power analysis for the behavioural sciences. 2nd edn. Hillsdale, NJ: Erlbaum, 1988.

21 Benjamini Y, Hochberg Y. Controlling the false discovery rate: a practical and powerful approach to multiple testing. J R STAT SOC B 1995;57:289-300.

22 Laine C, Weinberg DS. How can physicians keep up-to-date? Annu Rev Med 1999;50:99-110.

23 Sackett DL, Rosenberg WM. The need for evidence-based medicine. JRSM 1995;88:620-4.

24 Cross M, Smith E, Hoy D, et al. The global burden of rheumatoid arthritis: estimates from the global burden of disease 2010 study. Ann Rheum Dis 2014;73:1316-22.

$25 \mathrm{Ng} \mathrm{X}$, Low AHL, Chew L-C, et al. Disease patterns of rheumatology outpatients seen in a tertiary hospital serving a multi-ethnic, urban Asian population in Singapore. Int J Rheum Dis 2013;16:273-8.

26 Miedema HS, van der Linden SM, Rasker JJ, et al. National database of patients visiting rheumatologists in the Netherlands: the standard diagnosis register of rheumatic diseases. A report and preliminary analysis. Br J Rheumatol 1998;37:555-61.

27 Zhu Y, Pandya BJ, Choi HK. Prevalence of gout and hyperuricemia in the US general population: the National health and nutrition examination survey 2007-2008. Arthritis Rheum 2011;63:3136-41.

28 Cisternas MG, Murphy L, Sacks JJ, et al. Alternative methods for defining osteoarthritis and the impact on estimating prevalence in a US population-based survey. Arthritis Care Res 2016;68:574-80.

29 Deyo RA, Mirza SK, Martin BI. Back pain prevalence and visit rates: estimates from U.S. national surveys, 2002. Spine 2006;31:2724-7.

30 Birrell F, Arden NK, Conaghan PG, et al. Is it time for more rheumatologists to embrace osteoarthritis? Rheumatology 2005;44:829-30.

31 Pascual E, Sivera F. Why is gout so poorly managed? Ann Rheum Dis 2007;66:1269-70.

32 Chua JR, Jamal S, Riad M, et al. Disease burden in osteoarthritis is similar to that of rheumatoid arthritis at initial rheumatology visit and significantly greater six months later. Arthritis Rheumatol 2019;71:1276-84.

33 Smolen JS. Greetings from the editor 2019. Ann Rheum Dis 2019;78:1-2.

34 Patsopoulos NA, Analatos AA, loannidis JPA. Relative citation impact of various study designs in the health sciences. JAMA 2005;293:2362-6.

35 Cabezas-Clavijo A, Robinson-García N, Escabias M, et al. Reviewers ratings and bibliometric indicators: hand in hand when assessing over research proposals? PLoS One 2013;8:e68258.

36 Holden G, Rosenberg G, Barker K. Bibliometrics: a potential decision making aid in hiring, reappointment, tenure and promotion decisions. Soc Work Health Care 2005;41:67-92.

37 Tomkins A, Zhang M, Heavlin WD. Reviewer bias in singleversus double-blind peer review. Proc Natl Acad Sci U S A 2017;114:12708-13. 